\title{
Induções nas transformações do uso e ocupação do solo urbano em Ponta Grossa - PR
}

\author{
Inductions in the transformations of use and occupation of \\ urban land in Ponta Grossa (Paraná - Brazil)
}

\section{Inducciones en las transformaciones en el uso y ocupación del suelo urbano en Ponta Grossa (Paraná - Brasil)}

\author{
Ana Carolina Rodrigues Oliveira \\ anacr_oliveira@hotmail.com \\ Universidade Estadual de Ponta Grossa \\ Cicilian Luiza Löwen Sahr \\ cicilian@uol.com.br \\ Universidade Estadual de Ponta Grossa
}

Resumo: Neste artigo, busca-se compreender como o poder municipal, por intermédio das legislações urbanísticas derivadas dos planos diretores, especialmente os zoneamentos, procura moldar o espaço urbano. Primeiramente são feitas reflexões sobre o uso e ocupação do solo nos planos diretores. A seguir, avalia-se a estrutura de zoneamento de Ponta Grossa prevista nos planos, e quais as transformações nas densidades horizontais e verticais resultantes delas. Evidencia-se a indução de espaços privilegiados de especulação imobiliária pela abertura de processos de adensamento.

Palavras-chave: Plano Diretor. Zoneamento. Ponta Grossa.

Abstract: In this article, we intend to understand how municipal government, through the urban laws derived from master plans, especially the zoning, seeks to shape the urban space. Firstly, we reflect on the use and occupation of land in the master plan. Next, we evaluate the structure of zoning of Ponta Grossa provided in plans, and what changes in horizontal and vertical densities are the results from these. This study highlights the induction of privileged spaces of real estate speculation through the opening of densification processes.

Keywords: Master Plan. Zoning. Ponta Grossa.

Resumen: En este artículo se busca entender como el poder municipal, a través de las leyes derivadas de los planes directores, especialmente la zonificación, trata de dar forma al espacio urbano. Primeramente son hechas reflexiones del uso y ocupación del suelo en los planes directores. En seguida, se evalúa la estructura de zonificación de Ponta Grossa, establecida en los planes, y cuales las transformaciones en las densidades horizontales y verticales resultantes de esas. Se evidencia la inducción de los espacios privilegiados de la especulación inmobiliaria a través de los procesos de consolidación.

Palabras clave: Plan director. Zonificación. Ponta Grossa. 


\section{INTRODUÇÃO}

As cidades brasileiras possuem, por intermédio do zoneamento de uso e ocupação do solo, meios legais de ordenação do seu espaço. Esse instrumento, implantado há muitas décadas no país, consiste na divisão da cidade em zonas, com estabelecimento de limites de uso e intensidade de ocupação. Esse instrumento de ordenação urbana suscita um amplo debate sobre seus reais objetivos, uma vez que, via de regra, são utilizados para atender classes sociais dominantes.

As críticas ao uso de certos instrumentos de ordenação urbana tiveram maior destaque, sobretudo, a partir da década de 1980, quando movimentos sociais realimentaram o ideário democrático dos anos 1960 reprimido durante o período do regime militar. O Movimento Nacional pela Reforma Urbana (MNRU), por exemplo, tinha como pretensão coibir a especulação imobiliária, reduzir o nível de desigualdade socioeconômica e de segregação residencial, bem como, democratizar as práticas de planejamento e gestão urbana.

A emenda popular elaborada pelo MNRU resultou, de maneira bastante enxuta, em dois artigos da Constituição Federal de 1988 (artigos 182 e 183). A obrigatoriedade do plano diretor em municípios com mais de vinte mil habitantes estava então imposta, assim como a delegação de poderes à esfera municipal, expondo o caráter descentralizador da nova constituição. Entretanto, esses dois artigos necessitavam de regulamentação, o que aconteceu somente treze anos depois, com a lei n 10.257 (BRASIL, 2001), conhecida como Estatuto da Cidade.

A partir daí, tem-se então, um "arcabouço legal inédito sobre as cidades" (MARICATO, 2011, p. 102), fruto da reunião de movimentos, federações de sindicatos, associações de profissionais, ONG's, entre outros. No entanto, os planos diretores instrumentos básicos da política urbana - vêm perdendo sua credibilidade ao longo dos anos, dada a perduração de diversos problemas urbanos.

Grande parte da falta de credibilidade deve-se ao fato de que os planos diretores, não sendo autoaplicáveis, precisam ser regulamentados, e desta forma, acabam, em muitos casos, sendo considerados como "letra morta” (VILLAÇA, 2005, p. 28). Já os zoneamentos de controle de uso e ocupação do solo trazem normas ao setor privado, traduzidas - entre outros - em índices urbanísticos. Estes geram efeitos no espaço urbano, seja no estímulo à densificação ou na contenção desta em determinadas zonas.

O presente artigo propõe-se a investigar como esses índices foram regulados na cidade de Ponta Grossa nos anos de 1992 e 2011, por intermédio de leis de zoneamento, derivadas de planos diretores. Busca-se refletir sobre os efeitos deslas na estruturação e valorização do espaço urbano. Acredita-se que, no período em análise, o mercado, principalmente o imobiliário, teve cadeira cativa na formulação e na alteração das legislações urbanas. 


\section{PLANOS DIRETORES E USO DO SOLO: ALGUMAS REFLEXÕES}

A década de 1980 foi marcada pelo movimento da Reforma Urbana, que destacou a necessidade de o planejamento urbano ser pautado por princípios como a função social da cidade e a participação efetiva dos cidadãos, buscando-se uma maior democratização na gestão das cidades. O planejamento urbano teria também que viabilizar instrumentos de ordem jurídica e fiscal que tivessem a capacidade de enfrentar e controlar os problemas sociais e ambientais pelos quais as cidades brasileiras passavam.

Tais reivindicações populares, que visavam garantir ao cidadão o direito à cidade, tiveram reflexo na Assembleia Nacional Constituinte que levou à Constituição de 1988, alcunhada "Constituição cidadã" (ERENBERG, 2007, p. 55).

A nova constituição federal caracterizou-se por possuir um caráter descentralizador, contrastante com o período autoritário que sucedeu o golpe de 1964. Com a descentralização do sistema federativo brasileiro, foi reforçada a esfera municipalista de poder, que ganhou maior capacidade decisória. Reflexo disso foi a transferência de quase todas as responsabilidades de planejamento para os planos diretores municipais.

Dentre as constituições brasileiras, a de 1988 foi a primeira a mencionar o plano diretor, instrumento tornado obrigatório para cidades com mais de vinte mil habitantes, integrantes de regiões metropolitanas e com especial interesse turístico. Tal determinação vinculou-se aos art. 182 e 183, inseridos em um capítulo exclusivo da política urbana. O plano diretor passou a ser considerado então o "instrumento básico da política de desenvolvimento urbano" (BRASIL, 1988, art. 182, $\$ 1^{\circ}$ ). Logo, a propriedade urbana passaria a cumprir sua função social apenas quando atendesse "às exigências fundamentais de ordenação da cidade expressas no Plano Diretor" (art. 182, §2).

Entretanto, o capítulo de política urbana contido na Constituição necessitava de uma regulação mais densa, o que só veio a ocorrer treze anos depois, sob a forma da lei denominada Estatuto da Cidade (Lei 10.257, de 10 de julho de 2001). Ela atribuiu contornos práticos ao conceito jurídico - até então abstrato - de plano diretor (ERENBERG, 2007). Ou seja, o Estatuto da Cidade trouxe consigo importantes contribuições para a política urbana dos municípios, uma vez que viabilizou novos instrumentos de controle de uso do solo e regulamentou instrumentos antes sem aplicação. Como exemplos, cabe aqui ressaltar o Imposto Predial e Territorial Urbano (IPTU), progressivo no tempo, e a desapropriação com pagamento mediante títulos da dívida pública. Ambos visam penalizar os possuidores de terra urbana ociosa ou subutilizada, coibindo a especulação imobiliária e fazendo cumprir a função social da terra.

Os planos diretores são instrumentos mais abrangentes e poderosos que os zoneamentos, pois abarcam também questões relacionadas a saneamento, transporte, educação, saúde, habitação, desenvolvimento econômico e social, dentre outros temas (VILLAÇA, 2005). Os zoneamentos, todavia, têm forte influência no controle ou fomento da especulação imobiliária.

As prioridades do Estado brasileiro, todavia, vêm sendo as políticas de cunho econômico. Em relação às práticas de planejamento urbano, o exemplo mais notório 
é a crescente aliança entre o executivo municipal, o legislativo e o capital imobiliário (MARICATO, 2011). Nessa conjuntura, a tendência são os chamados planos estratégicos, uma nova roupagem aos planos diretores tradicionais, de caráter mais normativo. Este novo tipo de planejamento, que está em ascensão, é descrito por Souza $(2002 ; 2004)$ como sendo "extremamente amigo do mercado" (2004, p. 53), dando ênfase ao aumento da competitividade econômica da cidade para atrair e manter investimentos por meio da oferta de ampla infraestrutura e concessão de incentivos fiscais.

Para caracterizar esse estilo empresarialista de planejamento, Souza (2004, p. 53) utiliza o neologismo "mercadófilo", que deriva da fusão da palavra mercado com o radical filia (do grego philía: amizade). São traços integrantes deste as parcerias público-privadas, os projetos de revitalização de determinadas áreas e, principalmente, a forma permissiva de planejar o espaço urbano, estando marcadamente ajustada aos interesses do capital. Dessa forma, a preocupação central é a proteção de interesses privados em detrimento dos interesses da coletividade.

O planejamento urbano e os planos diretores apresentam diferentes mecanismos urbanísticos. O mais antigo e difundido é o zoneamento de uso e ocupação do solo. Ele possui normas que cabem, principalmente, ao setor privado obedecer e "deveriam ser instrumentos que ajudassem a garantir uma boa qualidade de vida para a população urbana, evitando a mistura de usos claramente incompatíveis entre si" (SOUZA, 2004, p. 30).

Além dos zoneamentos, os gestores têm a seu dispor instrumentos que interferem na produção do espaço urbano, como os tributos e os índices urbanísticos. Estes últimos impõem limites legais relativos à paisagem urbana e sua densidade, e devem andar juntos e de maneira integrada com os zoneamentos, pois os dois constituem "as ferramentas de uso mais corriqueiro no planejamento urbano" (SOUZA, 2002, p. 220). Portanto, a utilização que se faz de tais índices tem reflexos diretos no uso e ocupação do solo urbano. A verticalização, por exemplo, interfere na preservação da paisagem natural e na valorização do patrimônio histórico. Os afastamentos ou recuos no lote permitem manter a ventilação, luminosidade e privacidade dos moradores. Já a taxa de permeabilidade é de suma importância para a dinâmica ambiental das cidades, pois com ela se mantêm condições hidrológicas e térmicas aceitáveis.

Os planos diretores, as leis de zoneamento e os instrumentos urbanísticos, tomados para o espaço urbano de Ponta Grossa, serão objetos de reflexões nas seções que seguem.

\section{A ESTRUTURA URBANA DE PONTA GROSSA: CONCEPÇÃO DE POLOS E EIXOS}

O sítio urbano de Ponta Grossa possui características geomorfológicas peculiares, imprimindo ao seu relevo uma configuração bastante irregular. A topografia acentuada da cidade, de certa forma, condicionou o uso e a ocupação do solo urbano, interferindo no desenvolvimento da malha urbana e dos loteamentos. Foi, todavia, o poder público, influenciado pelo setor imobiliário e da construção civil, que induziu tal ocupação através de instrumentais legais. 
Para fins de comparação das duas últimas leis de zoneamento - que derivam de planos diretores - foram produzidos croquis que ilustram os diferentes usos previstos. A Lei de Zoneamento de 1992 deriva do Plano Diretor do respectivo ano (PONTA GROSSA, 1992a) e a Lei de Zoneamento de $2011^{1}$ do Plano Diretor de 2006 (PONTA GROSSA, 2006). A intenção é extrair destes planos diretores e zoneamentos quais foram as transformações no espaço urbano e o que o poder público visava ao criar, mudar ou manter o uso das zonas.

O primeiro plano diretor analisado é o de $1992^{2}$, elaborado a partir da obrigatoriedade imposta pela Constituição de 1988. À época, Ponta Grossa contava com 219.555 habitantes urbanos (IBGE, 1991) e havia passado recentemente pela discussão de sua Lei Orgânica Municipal - Lom (PONTA GROSSA, 1990), pormenorizando o que o plano diretor deveria conter. O plano foi elaborado pelo escritório de consultoria de Fortes Netto, sediado em Curitiba. O zoneamento proposto abria a cidade para receber comércio e serviços de maior complexidade.

O zoneamento urbano de 1992 é apresentado na Figura 1, onde pode ser observada a configuração proposta à cidade pela criação de polos e eixos comerciais e de serviços, distrito industrial e uma diversidade de zonas residenciais.

Com o Plano Diretor de 1992, previa-se a consolidação do chamado "Eixo Ponta Grossa", que atravessa a cidade no sentido leste-noroeste, estimulando o surgimento de três polos secundários: Nova Rússia, Uvaranas e Oficinas. Eles eram considerados como "núcleos comerciais existentes ou propostos (...), que se pretende dinamizar como alternativas de oferta de bens e serviços, em locais estratégicos da cidade, possuindo características e parâmetros semelhantes ao da Zona Central" (art. 8 , Lei Ordinária 4.856 - PONTA GROSSA, 1992b). Deste modo, a formação de núcleos alternativos visava desafogar o polo central.

Os eixos comerciais seriam acompanhados por zonas residenciais de maior densidade (ZR 4), induzindo a construção de edificações verticalizadas e oferecendo disponibilidade de infraestrutura e diversidade de usos. Previam-se ainda zonas residenciais de densidade média de ocupação e com diversidade de usos (ZR 3). Elas se destinariam aos conjuntos habitacionais, abrigando a parcela da população que não teria condições de arcar com imóveis bem localizados. A ZR 2 se caracteriza como de baixa densidade e pouca diversidade de usos, constituindo-se na maior parte da malha urbana. Destaque seria dado para a ZR 1, notadamente segregada (porém com ótima localização) e de pequena dimensão. Essa zona de baixa densidade de ocupação seria destinada exclusivamente às residências unifamiliares destinadas à classe alta.

1 Esta Lei ainda é um projeto, porém está prestes a ser aprovada pela Câmara Municipal. Optou-se por considerá-la por ser documento atual e por envolver as recentes demandas do poder público municipal, como a aprovação de uma Zona Especial para indústrias do ramo da Tecnologia (ZET), em vias de instalação.

2 Ele é, por ordem, o segundo que o município de Ponta Grossa teve. O primeiro data de 1967, fase do regime militar, e buscava preparar a cidade para absorver a função de polo agroindustrial em virtude de sua posição estratégica na convergência de corredores de exportação (café e soja). 
Figura 1 - Zoneamento Urbano de Ponta Grossa em 1992

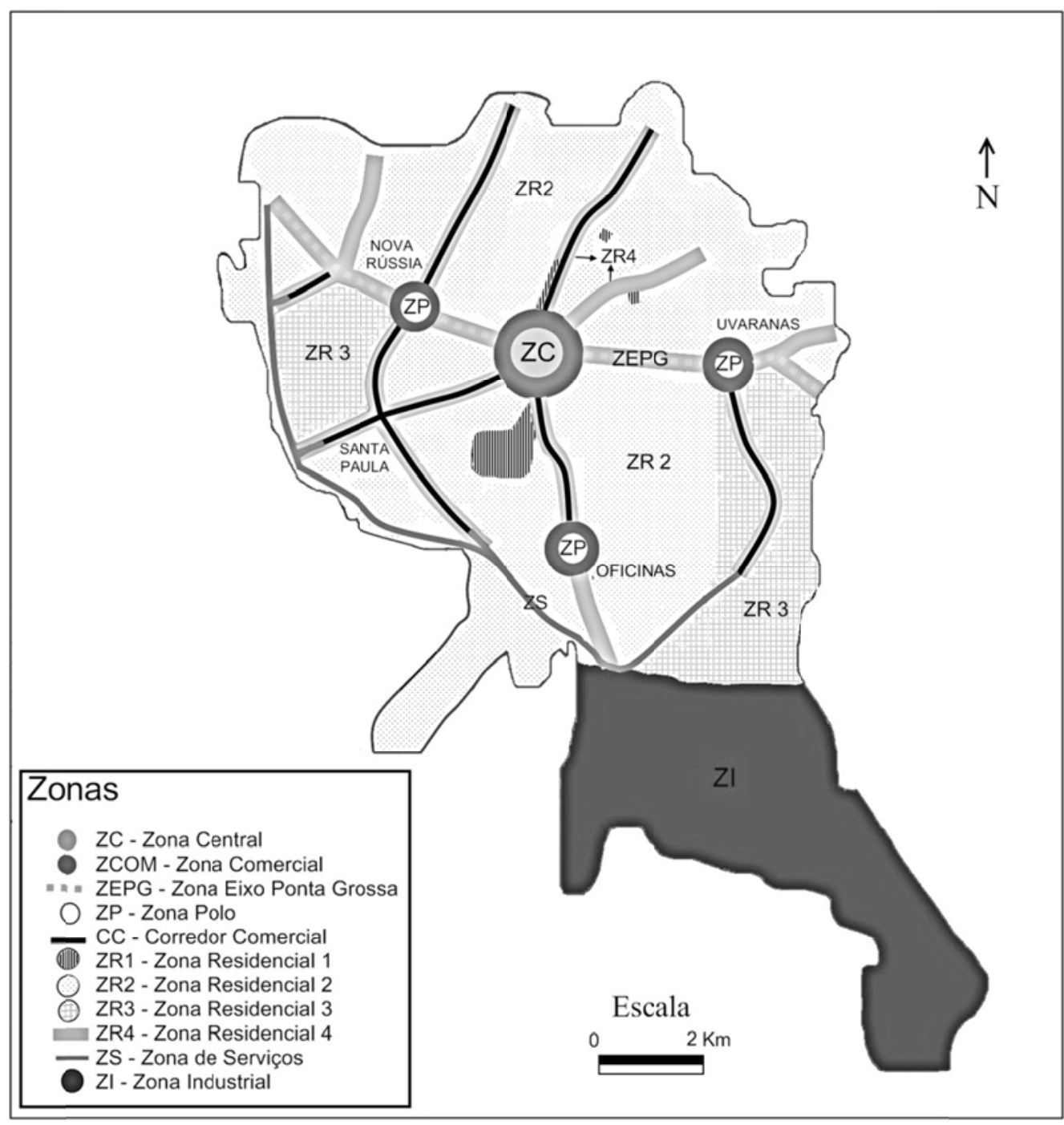

Fonte: PONTA GROSSA, 1992a

Elaboração: OLIVEIRA, A. C. R.

Nota: Na representação não consta a Zona Verde Especial e as Zonas de Serviços 1 e 2 foram representadas conjuntamente.

Em 2006, fruto da obrigatoriedade imposta pelo Estatuto da Cidade, Ponta Grossa atualiza seu plano diretor, rebatizado de "participativo". Desse modo, o município passa a integrar a nova onda de planos diretores. Para Cymbalista (2007, p. 28):

A partir de 2004, está em curso a Campanha Nacional do Plano Diretor Participativo, destinada a viabilizar a construção de mais de 1700 planos diretores nos municípios brasileiros que têm a obrigação de fazê-los até outubro de 2006, conforme as diretrizes do Estatuto da Cidade.

Embora com todas as possibilidades para se pensar em um plano de vanguarda, utilizando as inovações da Lei $\mathrm{n}^{\mathrm{o}} 10.257$, o resultado deste foi apenas um plano diretor clássico, pois embora utilize os novos instrumentos de regulação urbanística trazidos 
pelo Estatuto da Cidade, estes não são autoaplicáveis e, assim, até o momento não foram implementados. Apesar do chamamento deste plano fazer alusão à participação popular, o que se revelou foi apenas uma pseudoparticipação.

Diante disso, o zoneamento de 2011 (Figura 2) revela-se uma atualização do de 1992, permanecendo a estrutura da cidade em setores diferenciados por determinados usos urbanos. Não podem ser observadas grandes mudanças em termos de uso do solo. $\mathrm{O}$ escopo continuou sendo a estruturação em polos e eixos de comércio e serviços. No Zoneamento de 1992 havia as ZS 1 e 2, em 2011 consta no Projeto de Lei somente uma ZS. Embora as Zonas Polo tenham se extinguido, sua estrutura em forma de núcleo permanece e são agora denominadas de Zona Comercial. Os usos das antigas ZPolos são praticamente semelhantes aos da atual ZCom, assim como os índices urbanísticos, evidenciando que só houve uma mudança de denominação, não de objetivos.

Figura 2 - Zoneamento Urbano de 2011

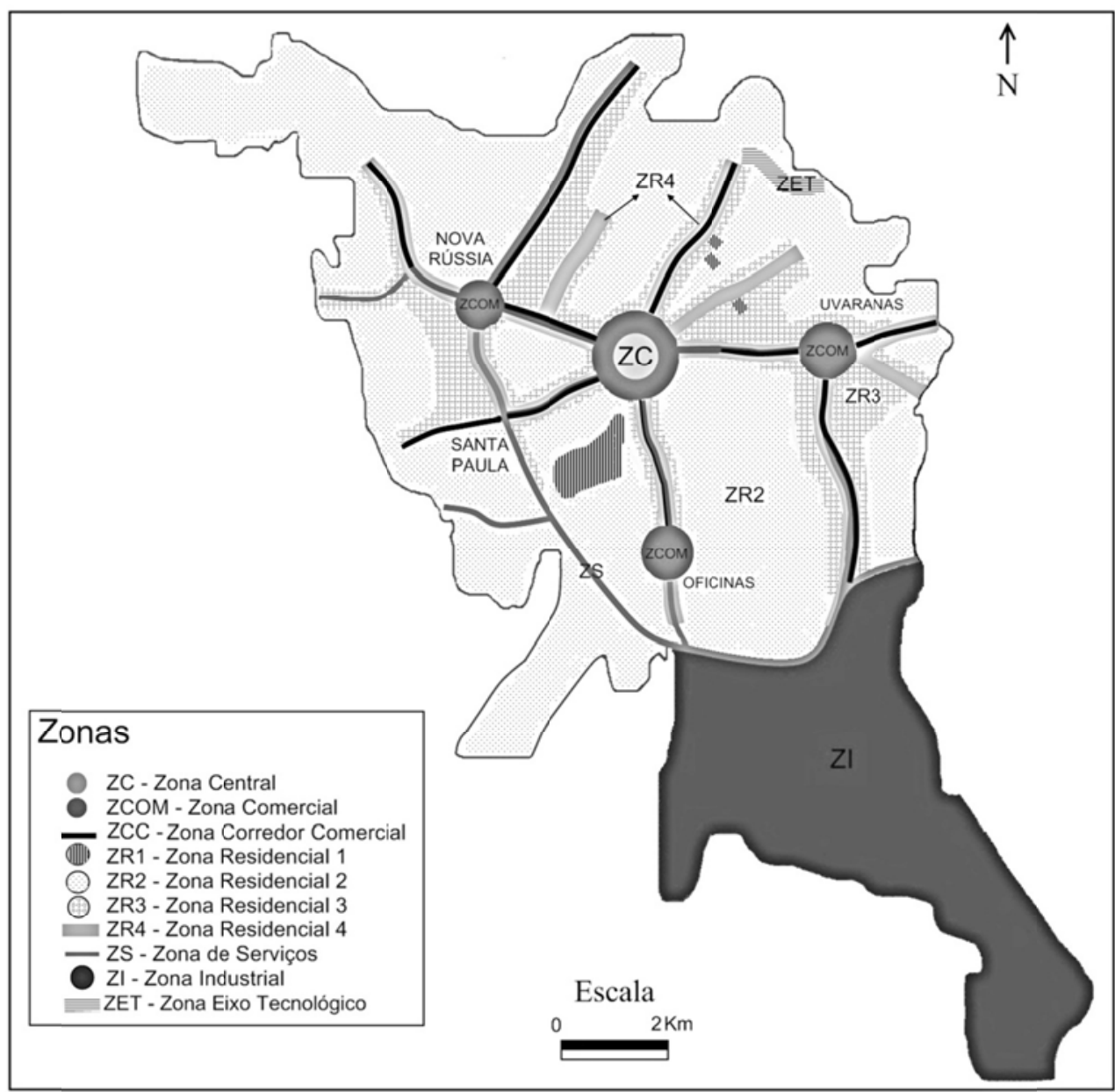

Fonte: PONTA GROSSA, 2011a

Elaboração: OLIVEIRA, A. C. R.

Nota: A Zona Verde Especial não está representada. 
Outra zona extinta no zoneamento foi a Zona Eixo Ponta Grossa, a qual atravessava a cidade em sentido leste-noroeste, possuindo a função de eixo estruturante da ocupação urbana. Entretanto, em seu lugar, ficam dispostos eixos compreendidos pelas Zonas Comerciais e Corredores Comerciais. A ZCom prevê as mesmas potencialidades de uso, porém tem índices urbanísticos que permitem maior adensamento de edificações. O Corredor Comercial tem um padrão de habitação menos verticalizada, mas com maiores dimensões e diversidade de usos que a ZEixo Ponta Grossa permitia em 1992. Essa alteração potencializa as zonas, tornado-as áreas atrativas ao mercado imobiliário.

Em relação às zonas residenciais, praticamente não houve alteração entre 1992 e 2011. A ZR1, reduto da classe alta em áreas bem infraestruturadas, planas e com acesso privilegiado ao centro se manteve. A ZR 3 - que apresenta um padrão de ocupação destinado às classes média e baixa - agora possuem maior expressividade em termos de área, servindo de transição entre as ZR 4, de alta densidade, e as ZR 2, de baixa densidade.

No zoneamento de 2011, a ênfase dada ao eixo de serviços é maior, uma vez que se propõe que ele atravesse a cidade no sentido norte-sul, e não mais contornando a cidade pela borda oeste, como em 1992. Onde antes existiam somente eixos de uso residencial de alta densidade (ZR 4) e comercial, a prioridade passa a ser os serviços. Trata-se de zonas que permitem usos comerciais de grande porte e pequenas indústrias não poluentes. A transposição do eixo de serviços corrobora com a posição do município enquanto maior entroncamento rodoferroviário do estado, tendo ligação ao norte com as cidades em direção a São Paulo; a Sudeste com Curitiba; a noroeste com Londrina, Maringá e a oeste com Guarapuava.

Por fim, há a inserção para 2011 de uma nova zona, intitulada Zona Eixo Tecnológico (ZET), a nordeste do Centro comercial, nas proximidades da Universidade Tecnológica Federal do Paraná (UTFPR). Tal zona será destinada a abrigar comércios e serviços voltados ao desenvolvimento de tecnologias, com índices urbanísticos equivalentes aos da Zona de Serviços (PONTA GROSSA, 2011a). Prevê-se a ZET com plantas de dimensões menores do que as permitidas na Zona Industrial.

O poder público municipal pretende instalar nessa área um Parque Ecotecnológico com aproximadamente $720 \mathrm{mil} \mathrm{m}^{2}$, firmando uma parceria com empresas privadas - oito já receberam doação de terreno - e com a Universidade Técnica Federal do Paraná (UTFPR). Sua conotação ambiental se deve à reserva de áreas preservadas, nativas e recuperadas (PONTA GROSSA, 2011b).

O então espírito empresarialista na forma de gestão urbana, de que este artigo tratou na seção anterior, é confirmado com as transformações no zoneamento urbano previsto e nas informações supracitadas. As parcerias público-privadas são traços marcantes de um planejamento urbano ajustado aos interesses do capital.

Verificou-se, portanto, que houve poucas transformações na perspectiva de mudança social em termos de planejamento do uso do solo em Ponta Grossa no período analisado. Exemplo disso se veem, na ausência do instrumento, Zonas Especiais de Interesse Social (ZEIS) no zoneamento de 2011. De fato, houve uma contribuição à reprodução da estrutura urbana vigente, fragmentada socialmente, e novos espaços se tornaram aptos 
para reprodução concentrada do capital. Aprofunda-se esta análise na próxima seção, voltando-se para reflexões em termos de planejamento da ocupação do solo com base nos índices urbanísticos.

\section{TRANSFORMAÇÕES NA OCUPAÇÃO DO SOLO URBANO: DENSIDA- DES HORIZONTAIS E VERTICAIS}

A Carta de Atenas - documento resultante do Congresso Internacional de Arquitetura Moderna (Ciam) no ano de 1933 - é reflexo dos debates acerca dos problemas pelos quais as cidades passavam à época. A partir dela foram se introduzindo os regulamentos construtivos na organização das cidades (PANTOJA, 2006).

O uso de parâmetros ou índices urbanísticos no planejamento das cidades brasileiras está previsto em legislação federal, Lei de Parcelamento do Solo Urbano $n^{0} 6.766$ (BRASIL, 1979), e em dispositivos municipais. Nas leis de zoneamento de Ponta Grossa, 1992 e 2011, os índices urbanísticos regulamentados dizem respeito à dimensão mínima do lote, ao limite de altura das edificações, à taxa de ocupação para a base e torre, ao afastamento das edificações e à taxa de permeabilidade.

Esses instrumentos, considerados tradicionais com o advento do Estatuto das Cidades de 2001, visam regular as densidades tanto horizontais quanto verticais de ocupação do espaço urbano. Juntamente com o zoneamento de uso do solo, eles interferem no arranjo "físico" da cidade, com efeitos sobre o ordenamento espacial.

Considerando a importância de tais instrumentos, eles foram empregados neste artigo para uma análise comparativa da legislação derivada dos Planos Diretores de Ponta Grossa de 1992 e 2006, buscando apontar os espaços induzidos pelo poder público à especulação imobiliária. Como parâmetro comparativo para avaliar as transformações nas densidades verticais e horizontais, utilizou-se um índice síntese, que se denominou "potencial máximo construtivo" (PMC). A partir dele, foi possível avaliar a área máxima que pode ser construída em um lote, somando-se as metragens de todos os pavimentos.

Para se obter o PMC, foi utilizado o Coeficiente de Aproveitamento (CA), o qual interfere na densidade demográfica e habitacional. Trata-se de um instrumento que visa estimular ou não o adensamento das zonas. Seu valor deve ser diferenciado por zona e, em regra, depende da capacidade de infraestrutura instalada em cada uma destas. Ele resulta da relação entre a área total construída e a área total do lote 3 .

O Gráfico 1 apresenta os PMC para cada zona de Ponta Grossa em 1992 e 2011. Para melhor representação, não consta no gráfico a Zona Industrial, com potencial construtivo de 3.000 m² $^{2}$ (PONTA GROSSA, 1992b; 2011a), pois a comparação com as demais zonas, com menor potencial construtivo, potencialmente distorceria a análise.

3 Exemplo: Considerando um lote de $360 \mathrm{~m}^{2}$ e uma edificação de $180 \mathrm{~m}^{2}$, o CA será de 0,5. No caso da edificação ocupar a metragem total do lote, o CA será igual a 1. Para o potencial máximo construtivo, a relação ocorre da seguinte maneira: $\mathrm{PMC}=$ área lote $\times \mathrm{CA}$. 
Gráfico 1 - Potencial Máximo Construtivo, segundo Zoneamentos de Ponta Grossa de 1992 e 2011

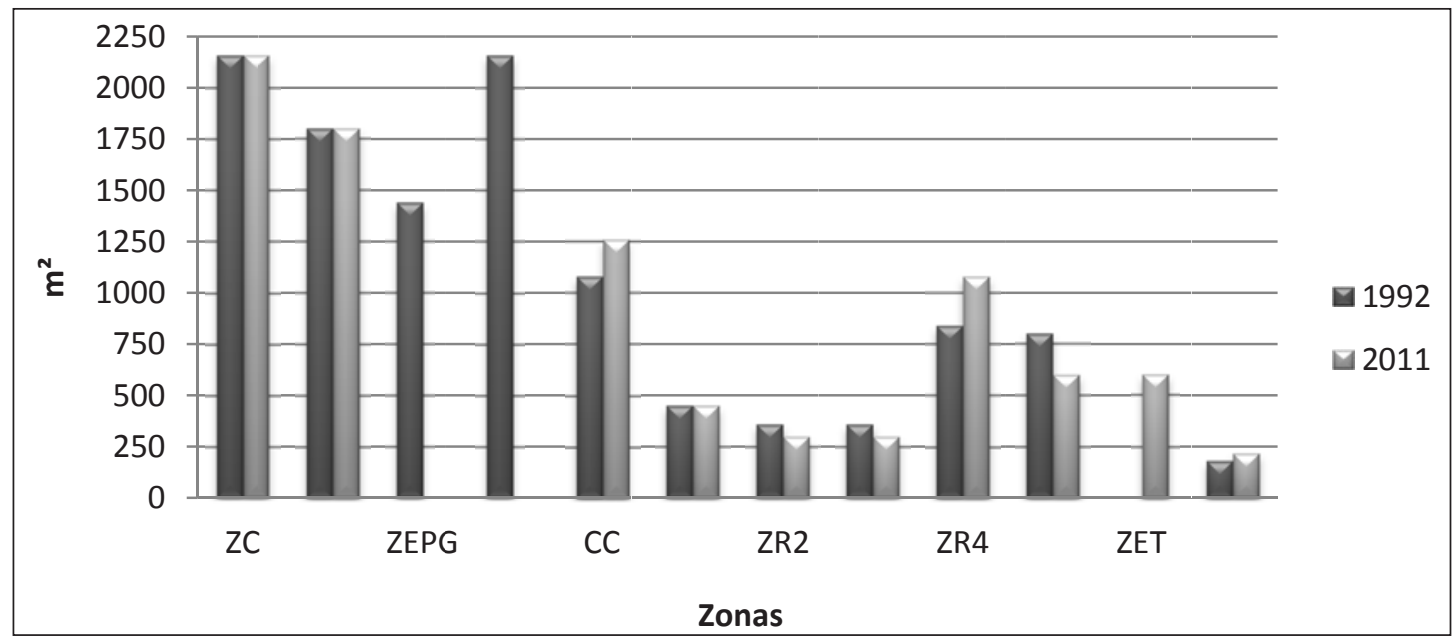

Fonte: PONTA GROSSA, 1992a; 2011a.

Elaboração: OLIVEIRA, A. C. R

Observa-se, como primeiro resultado, que se permite um adensamento maior nas zonas predominantemente comerciais (ZC - Zona Central; ZCOM - Zona Comercial; ZEPG - Zona Eixo Ponta Grossa; ZPOLO - Zona Polo; CC- Corredor Comercial). Considerando as zonas residenciais, a ZR 4 é a que possui os maiores valores. Reafirma-se, assim, uma estrutura de polos e eixos de adensamento na cidade.

Como em 1992 havia duas Zonas de Serviço, foi feita a média entre os valores para confrontar com o valor de 2011. Com relação às zonas extintas (ZEPG e ZPOLO), mantiveram-se os índices de 1992 para comparação com as zonas que hoje as representam, quais sejam ZCOM e CC.

As ZPOLOs de 1992, que em 2011 são as ZCOMs, têm potencial construtivo semelhante à ZC, indicando quatro áreas privilegiadas em termos de especulação imobiliária: o centro e os polos Nova Rússia, Oficinas e Uvaranas. Estas áreas permitem mais pavimentos e maior taxa de ocupação da torre em 2011 do que em 1992. A antiga ZEPG foi substituída por eixos da ZCOM e CC. Apesar de a zona CC de 2011 permitir menos pavimentos do que a ZEPG admitia em 1992, esta tem maiores taxas de ocupação (tanto da base quanto da torre) e maiores dimensões mínimas dos lotes (testada e área), mantendo a atratividade desses eixos para o capital imobiliário (PONTA GROSSA, 1992b, 2011a).

Comparando os dois momentos para a ZR4, nota-se que o potencial construtivo aumentou de forma significativa entre 1992 e 2011. Vale lembrar que nessa zona residencial, o potencial construtivo é mais elevado quando comparado às demais zonas residenciais. Nestas zonas, induz-se o adensamento por serem elas que acompanham os eixos comerciais e também os eixos de circulação. Tem-se nelas também uma grande oportunidade de especulação imobiliária induzida pelo poder público.

Para examinar o incentivo ao adensamento vertical, selecionou-se o índice referente à altura máxima permitida para as construções. Assim, tornou-se possível, a partir do Gráfico 2, a comparação entre o gabarito de altura de 1992 e 2011. Foram excluídas da 
ilustração as zonas Central, Industrial e Verde Especial, que não possuem valores referentes a esse índice. No caso específico da Zona Central, não há limites de altura, se forem respeitadas a Taxa de Ocupação e o Coeficiente de Aproveitamento. Isso significa, via de regra, grande número de pavimentos, ou seja, os maiores gabaritos de altura da cidade.

Gráfico 2 - Altura máxima permitida em número de pavimentos segundo os Zoneamentos

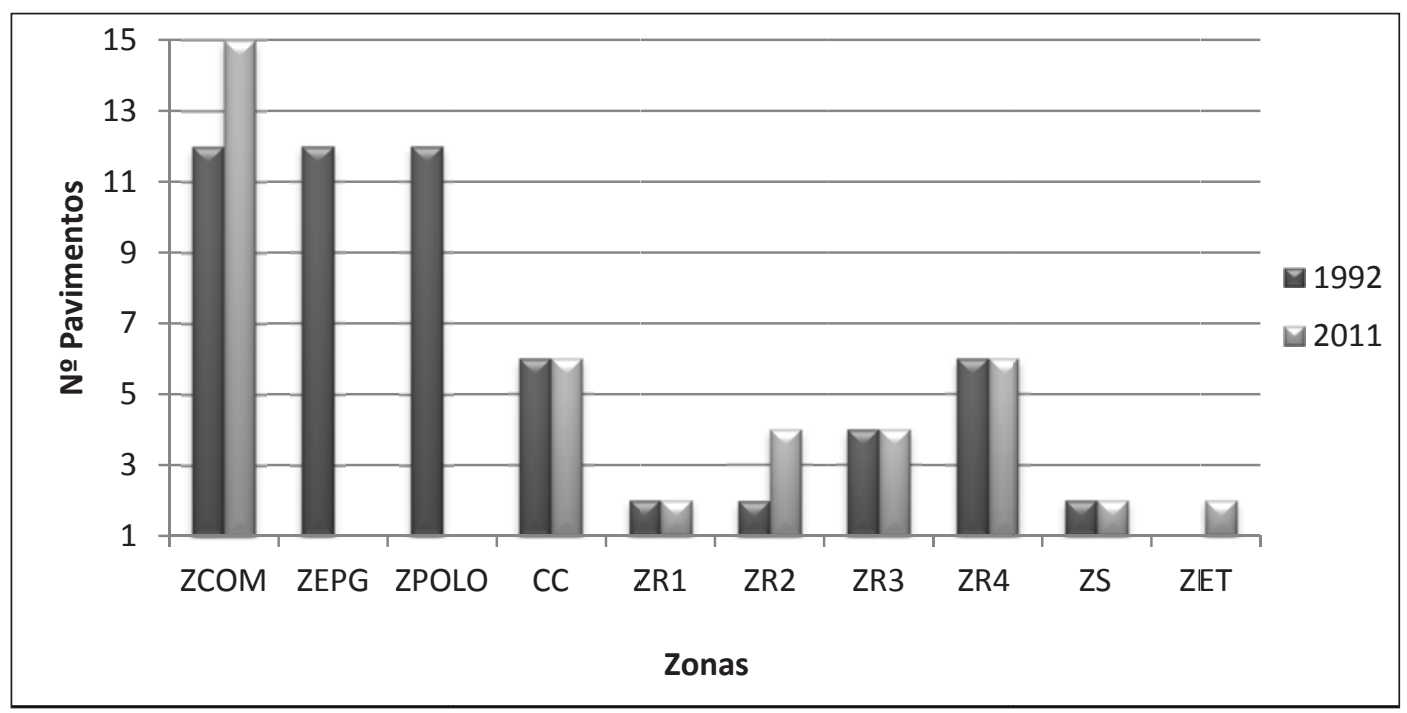

Fonte: PONTA GROSSA, 1992a; 2011a.

Elaboração: OLIVEIRA, A. C. R.

As ZR 4 e CC podem ter até seis pavimentos, sendo as zonas com maior potencialidade de verticalização em 2011, depois da ZCOM que pode atingir onze. A ZCOM representa área privilegiada para investimentos, tendo o maior gabarito de altura no período analisado, além de ter expandido sua área de abrangência. Destaque também pode ser atribuído à ZR2 por ter sido aquela que, proporcionalmente, teve o maior incremento em termos de gabarito de altura entre 1992 e 2011.

Pode-se dizer, portanto, que a configuração em eixos de adensamento torna altamente valorizadas as zonas ZCOM, CC e ZR4, uma vez que maiores coeficientes de aproveitamento, potencial construtivo e possibilidade de verticalização se tornam um atrativo à construção civil e ao setor imobiliário. A maior capacidade de aproveitamento dos terrenos, além da privilegiada acessibilidade e disponibilidade de serviços e comércio são valiosas moedas de troca no mercado.

Essas zonas são bastante visadas pelos especuladores, agraciados com o fato de que em Ponta Grossa não há regulamentação para os mecanismos que visam combater a especulação imobiliária, como o parcelamento e utilização compulsórios, o IPTU progressivo no tempo e a desapropriação com pagamento em títulos. A atuação desses grupos em áreas bem providas de infraestrutura é visível, uma vez que não há qualquer sanção.

A partir dos Gráficos 1 e 2, também é possível depreender determinadas peculiaridades para as demais zonas residenciais. A ZR 1 possui um alto potencial construtivo, maior que as ZR 2 e 3, porém, são permitidos poucos pavimentos, no máximo dois. 
Dentre as quatro zonas residenciais, é a ZR 1 que tem as maiores dimensões mínimas do lote: $15 \mathrm{~m}$ de testada e $450 \mathrm{~m}^{2}$ de área. Ela é caracterizada como de baixa densidade de ocupação e a única exclusivamente destinada para habitações unifamiliares (PONTA GROSSA, 1992b, 2011a). A tipologia construtiva que resulta dessas diretrizes é de grandes residências com alta qualidade arquitetônica. É imprescindível salientar que nos dois momentos analisados, não houve qualquer alteração dos índices urbanísticos dessa zona, mantendo-a altamente valorizada.

O limite imposto ao potencial de edificabilidade e à densidade na ZR 1 acabou por gerar um novo fator que garante a sua valorização, a exclusividade de uso. $\mathrm{O}$ aparente “... pequeno rendimento decorrente da baixa densidade é largamente compensado pela valorização devida ao prestígio e exclusividade" (ROLNIK, 1997, p. 188). Desta forma, a legislação urbanística vem desempenhando um papel de proteção e reprodução da valorização de loteamentos como os nela encontrados.

As ZR 2 e 3 tiveram redução no seu potencial construtivo. No caso da ZR 2, aumentou sua possibilidade de verticalização, se igualando à $Z R$ 3. Em relação às dimensões mínimas do lote, as duas zonas apresentaram reduções: de $12 \mathrm{~m}$ para $10 \mathrm{~m}$ de testada, e de 360 para $300 \mathrm{~m}^{2}$ de área mínima dos lotes (PONTA GROSSA, 1992b, 2011a). Esses valores menores se ajustam ao padrão financeiro daqueles que não têm condições de construir um imóvel na ZR 4, e, muito menos, na ZR 1. Menores áreas, mais pavimentos e grande variedade de usos desencadeiam uma maior concentração populacional. Isso, aliado ao fato de que estas zonas são mais periféricas e, assim, menos valorizadas pelo mercado, concentrando a população de menor poder aquisitivo.

Essa atual conjuntura do espaço urbano pontagrossense ilustra a fala de Souza (2005, p. 90), quando afirma que:

O Estado, tradicional promotor de segregação residencial (junto com o capital imobiliário, ou tendo este por trás...), ao investir diferencialmente nas áreas residenciais da cidade e estabelecer estímulos e zoneamentos e outras normas de ocupação do espaço que consolidam a segregação, atua, também, como agente repressor, via de regra, na tentativa de 'colocar os pobres no seu devido lugar'.

Outra zona que teve modificação entre 1992 e 2011 foi a Zona Verde Especial (ZVE). A lei não determina o tamanho mínimo do lote, então se tomou como base uma área de $360 \mathrm{~m}^{2}$, somente para fins de comparação. O Potencial Construtivo da ZVA que era de $180 \mathrm{~m}^{2}$ em 1992 atingiu $216 \mathrm{~m}^{2}$ em 2011 (PONTA GROSSA, 1992b, 2011a). Pode-se atribuir a essa mudança a crescente pressão por espaços livres por parte da construção civil e do mercado imobiliário, aliada a um enfraquecimento das políticas ambientais da cidade, uma vez que tais áreas deveriam ser cada vez mais restringidas às intervenções humanas.

A ocupação do solo urbano também pode ser examinada através da densidade horizontal. Para essa análise, foi escolhida a Taxa de Ocupação (TO), a qual significa a relação percentual entre a projeção da edificação e a área total do terreno. Entre outras palavras, ela representa a porcentagem do terreno sobre o qual há edificação. Não tem, portanto, relação direta com o número de pavimentos. 
A Taxa de Ocupação de um terreno interfere nas condições de salubridade. Ela pode auxiliar no controle da insolação e da ventilação, reduzir o volume de escoamento superficial devido ao aumento da permeabilidade do solo, produzir efeitos estéticos mais agradáveis, enfim, melhorar as condições ecológicas e de conforto do espaço urbano (PANTOJA, 2006). Em Ponta Grossa, a Taxa de Ocupação é diferenciada entre a taxa da base e a da torre da edificação. Neste estudo, optou-se por utilizar somente a da base por se tratar de um processo de caráter comparativo (Gráfico 3).

Gráfico 3 - Taxa de Ocupação da Base, segundo os Zoneamentos de Ponta Grossa de 1992 e 2011

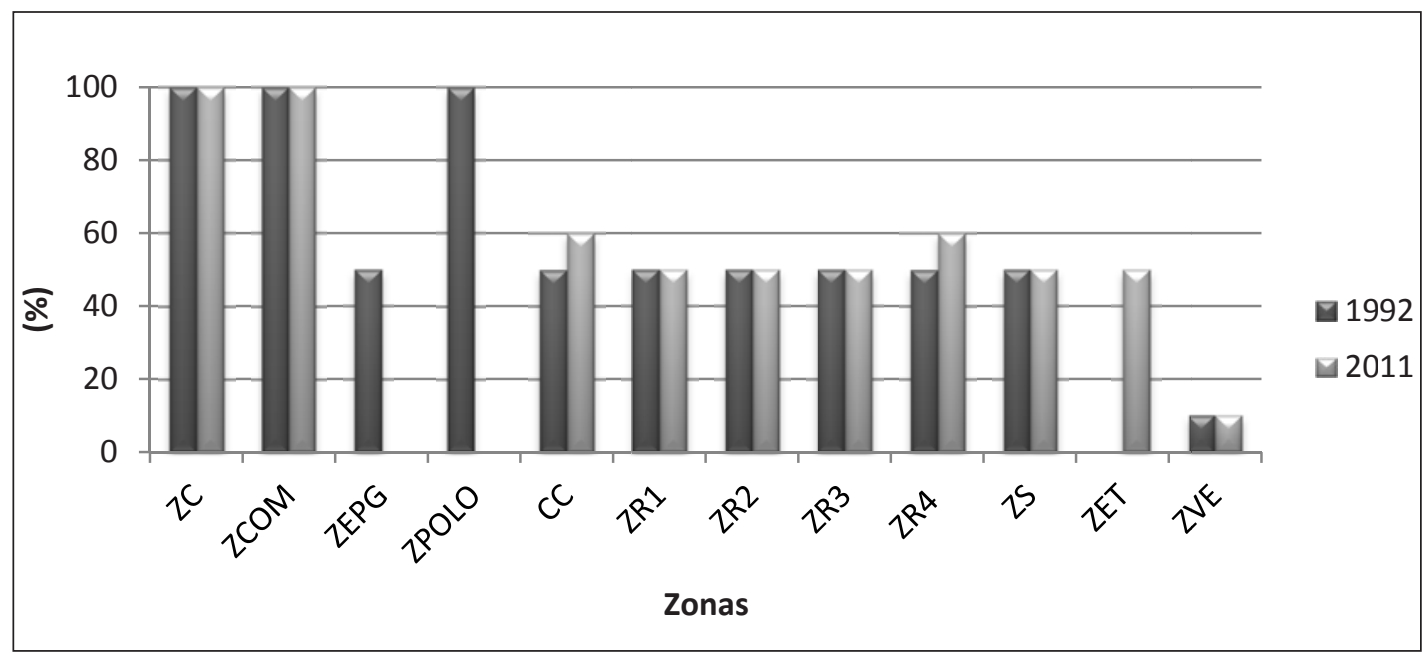

Fonte: PONTA GROSSA, 1992b; 2011a. Elaboração: OLIVEIRA, A. C. R.

O Gráfico 3 expõe uma tendência de manutenção das Taxas de Ocupação. Apenas nas zonas CC e ZR 4, houve aumento desta, portanto, nestas zonas o percentual do terreno que poderá ser edificado passou a ser maior em 2011. Fica evidente, mais uma vez, o peso que a ZR4 possui na produção do espaço construído. Em todos os parâmetros analisados, configurou-se como um eixo fértil de investimentos tanto do governo municipal com provimento de infraestrutura - quanto do mercado imobiliário e da construção civil. Esta conjuntura também se aplica à ZR1, que abriga classe de maior poder aquisitivo da sociedade e que conta com a garantia da preservação dos índices urbanísticos, mantendo, assim, o padrão habitacional vigente, muito lucrativo para o mercado habitacional.

Em suma, o zoneamento de uso e ocupação do solo urbano em Ponta Grossa contribui com o processo de segregação socioespacial e com o processo de especulação imobiliária. Isto reforça "os privilégios urbanos adquiridos pelas classes dominantes ao longo da sua hegemônica atuação de 500 anos" (FERREIRA E MOTISUKE, 2007, p. 37). Tal hegemonia pode ser vista tanto na segregação de uso como na determinação de índices urbanísticos que lhe permitem grande valorização imobiliária. 


\section{CONSIDERAÇÕES FINAIS}

As leis de zoneamento são importantes ferramentas para regular a densidade urbana e sua volumetria. Elas produziram, em Ponta Grossa, efeitos na paisagem urbana, induzindo, entre outros, corredores de verticalização, polos de comércio e áreas exclusivamente residenciais voltadas às populações de maio poder aquisitivo. Infelizmente, tais leis não se voltaram para uma concepção de justiça social.

Investigando e comparando as leis de uso e ocupação solo no espaço urbano de Ponta Grossa, percebeu-se que o planejamento do uso não induziu grandes transformações, pelo contrário, observou-se a manutenção da mesma concepção no período de 1992 a 2011. O mesmo não ocorreu com o planejamento da ocupação do solo urbano. Avaliando o emprego dos parâmetros urbanísticos clássicos, observou-se a indução de espaços privilegiados de especulação imobiliária por intermédio da abertura de processos de adensamento vertical e horizontal de determinadas áreas.

Conforme visto pelos índices urbanísticos, o estímulo ao adensamento das zonas ZCOM, ZC, ZR4 e CC fomenta o mercado imobiliário. Esse processo ganha mais abertura na cidade, uma vez que as políticas públicas de preservação do patrimônio histórico-cultural são insuficientes e frágeis, dado que vários são os episódios de destruição/descaso com prédios históricos na cidade.

Em relação à forma de uso e ocupação planejada, fica então evidente o descompasso entre o idealizado nos movimentos sociais pela Reforma Urbana, que criaram mecanismos para a produção de uma cidade mais igualitária, e o cenário atual da cidade de Ponta Grossa. Enquanto expressiva parcela da população habita áreas longínquas ou ambientalmente frágeis em fundos de vale, que não interessam ao mercado, os gestores municipais atendem aos interesses privados e de determinados segmentos do mercado. Isso reproduz, cada vez mais, a exclusão social vivenciada pela maioria das cidades, dando luz à ineficácia social da legislação urbana.

Ficou explícita, deste modo, a preocupação exclusiva por parte do Plano Diretor e do Zoneamento de Ponta Grossa com a ordenação do espaço físico, em detrimento de preocupações de cunho sociais. Isso reforça a ideia de que "o Estado possui limitações enquanto um promotor de justiça social” (SOUZA, 2004, p. 70), no que tange à transformação do cenário de produção urbana desigual.

\section{REFERÊNCIAS}

BRASIL. Lei no 6.766 de 19 de dezembro de 1979. Dispõe sobre o Parcelamento do Solo Urbano e dá outras providências. Diário Oficial da União, Brasília, DF, 20 dez.1979.

. Constituição da República Federativa do Brasil. Brasília: Senado Federal, 1988.

. Lei n ${ }^{\circ} 10.257$ de julho de 2001. Regulamenta os arts. 182 e 183 da Constituição Federal, estabelece diretrizes gerais da política urbana e dá outras providências. Diário Oficial da União, Brasília, DF, 11 jul. 2001 
CYMBALISTA, R. Instrumentos de planejamento e gestão da política urbana: um bom momento para uma avaliação. In: BUENO, Laura Machado de Mello; conceitos de planejamento territorial. São Paulo: Annablume, 2007. (Org.). Plano diretores municipais: novos

ERENBERG, J. J. Sentido e alcance do princípio da função social da propriedade urbana: a ausência de plano diretor e o conteúdo mínimo dedutível do sistema da Constituição Federal Brasileira de 1988. Dissertação (Mestrado em Direito do Estado) Pontifícia Universidade Católica de São Paulo. São Paulo, 2007.

FERREIRA, J. S. W.; MOTISUKE, D. A efetividade da implantação de Zonas Especiais de Interesse Social no quadro habitacional brasileiro: uma avaliação inicial. In: BUENO, Laura Machado de Mello; CYMBALISTA, Renato (Orgs.). Plano diretores municipais: novos conceitos de planejamento territorial. São Paulo: Annablume, 2007.

IBGE. Censo Demográfico - Paraná. Rio de Janeiro: IBGE, 1991.

MARICATO, E. O impasse da política urbana no Brasil. Petrópolis, RJ: Vozes, 2011.

PANTOJA, L. Parâmetros urbanísticos para habitação de interesse social: uma análise crítica para as Rocas em Natal/RN. Dissertação (Pós- Graduação em Arquitetura e Urbanismo). Universidade Federal do rio Grande do Norte. Natal, 2006.

PONTA GROSSA. Projeto de Lei. Dispõe sobre o Zoneamento de Uso e Ocupação do Solo do Município de Ponta Grossa. Ponta Grossa, 2011a.

Parque ecotecnológico recebe nova indústria. Ponta Grossa, dez. 2011b. Disponível em: http:/ / www.pontagrossa.pr.gov.br/node/11903. Acesso em: 5 jan. 2012.

Plano Diretor Participativo do Município de Ponta Grossa. 2006. Atualiza a Lei do Plano Diretor do município de Ponta Grossa em consonância com as novas diretrizes da revisão do Plano Diretor e dá outras providências. Disponível em: <http://www.jusbrasil.com.br/legislacao/405526/lei-8663-06ponta-grossa-pr>. Acesso em: 03 fev. 2012.

Plano Diretor de Ponta Grossa. Curitiba: Fortes Netto, 1992a.

Lei Ordinária $n^{\circ} 4.856$ de 28 de dezembro de 1992. Dispõe sobre o zoneamento de uso e ocupação do solo das áreas urbanas do município de Ponta Grossa e dá outras providências. 1992b. Disponível em: <http://www.jusbrasil.com.br/legislacao/419362/lei-4856-92-ponta-grossa-pr> Acesso em: 03 fev. 2012.

Lei Orgânica do Município de Ponta Grossa. Ponta Grossa: Inpag, 1990.

Plano Diretor de Ponta Grossa. Ponta Grossa: Codem, 1967.

ROLNIK, R. A cidade e a lei: legislação, política urbana e territórios na cidade de São Paulo - São Paulo: Studio Nobel: Fapesp, 1997.

SOUZA, M. L. de. ABC do desenvolvimento urbano. 2. ed. Rio de Janeiro: Bertrand Brasil, 2005.

Planejamento urbano e ativismos sociais. São Paulo: UNESP, 2004.

Mudar a cidade: uma introdução crítica ao planejamento e à gestão urbanos. Rio de Janeiro: Bertrand Brasil, 2002.

VILLAÇA, F. As ilusões do plano diretor. São Paulo: 2005.

Disponível em: <http://www.flaviovillaca.arq.br/pdf/ilusao_pd.pdf>. Acesso em: 11 out. 2011.

Recebido em 07/02/2012.

Aceito para publicação em 13/03/2012. 